\title{
Acreditação Hospitalar: proposição de roteiro para implantação
}

\author{
Hospital Accreditation: a proposal of framework \\ for implementation
}

\author{
Gabriel Pedro Alástico \\ José Carlos de Toledo'
}

\begin{abstract}
Resumo: No Brasil, o Sistema Hospitalar é caracterizado pela precariedade em procedimentos e recursos, levando à falta de qualidade nos serviços prestados aos pacientes. Essa realidade pode ser explicada, em parte, por deficiências no sistema de gestão hospitalar. Nesse contexto, a difusão e a implantação do Sistema de Acreditação Brasileiro, coordenado pela ONA - Organização Nacional de Acreditação, têm se mostrado uma importante iniciativa. Apesar dos esforços de estruturação deste Sistema de Acreditação, muitos hospitais encontram dificuldades para implantar os requisitos deste sistema de gestão. Este artigo contribui para essa questão propondo um roteiro orientativo de adequação da gestão hospitalar aos requisitos de Acreditação, visando apoiar os gestores hospitalares na implantação desses requisitos. Um roteiro preliminar foi gerado a partir de uma pesquisa exploratória realizada em três hospitais Acreditados e de uma revisão bibliográfica. O roteiro preliminar foi testado e aperfeiçoado por meio de uma pesquisa-ação realizada em um hospital público de pequeno porte. A aplicação do roteiro proposto auxilia os gestores a melhor compreenderem e conduzirem o processo de Acreditação e seus requisitos.
\end{abstract}

Palavras-chave: Acreditação Hospitalar. Roteiro para implantação. Gestão hospitalar.

\begin{abstract}
The Brazilian Hospital System is characterized by ineffectiveness in procedures and services, which leads to poor quality services for patients. This can be explained by problems in the hospital management system. In this setting, the Accreditation system, coordinated by NAO (National Accreditation Organization), became an important initiative. Despite efforts towards structuring a Brazilian Accreditation, hospitals still have some difficulty in implementing Accreditation requirements. This paper contributes in this direction, proposing an framework for adequacy of hospital management to the Accreditation requirements, for helping hospital managers to implement them. A preliminary framework was developed based on an exploratory research conducted in three accredited hospitals and also based on literature review. The preliminary framework was tested and improved by means of an action research in a small-sized hospital. The implementation of the framework proposed helped the hospital managers to better understanding the Accreditation process and achieve the Accreditation requirements.
\end{abstract}

Keywords: Hospital Accreditation. Framework for implementing. Hospital management.

\section{Introdução}

Os hospitais, ao atender demandas de atores sociais como Governo, pacientes, financiadores e planos de saúde, têm incorporado, em suas atividades, procedimentos e processos que os diferenciem da concorrência e melhorem o padrão de qualidade dos serviços prestados (GURGEL JUNIOR; VIEIRA, 2002; MATHEIS, 2006; VECINA NETO; MALIK, 2007; PERTENCE; MELLEIRO, 2010; JOINT COMMISSION, 2011).

Na perspectiva de obter padrões assistenciais mais elevados, vários países têm aplicado iniciativas que atestem a competência e a qualidade na prestação dos serviços hospitalares, estimulando a melhoria da qualidade da assistência, o que resultou no surgimento, a partir dos EUA, do programa de Acreditação Hospitalar (FELDMAN; GATTO; CUNHA, 2005; D'INNOCENZO; ADAMI; CUNHA, 2006; BONATO, 2007; PERTENCE; MELLEIRO, 2010; FORTES; MATTOS; BAPTISTA, 2011). Este busca reduzir desperdícios de recursos e tornar o gerenciamento hospitalar mais eficiente, com processos e serviços realizados em padrões de excelência que garantem a segurança e a satisfação dos pacientes (ANTUNES; RIBEIRO, 2005; BURMESTER; PEREIRA; SCARPI, 2007; KLUCK et al., 2008; LAGIOIA et al., 2008; NOGUEIRA, 2008; PERTENCE; MELLEIRO, 2010).

\footnotetext{
${ }^{1}$ Departamento de Engenharia de Produção, Centro de Ciências Exatas e de Tecnologia, Universidade Federal de São Carlos - UFSCar, Rod. Washington Luís, Km 235, CEP 13565-905, São Carlos, SP, Brasil, e-mail: gabriel_alastico@ yahoo.com.br; toledo@dep.ufscar.br Recebido em 15/3/2012 — Aceito em 21/8/2013
}

Suporte financeiro: A pesquisa foi financiada pela FAPESP. 
A obtenção da Acreditação é percebida como um diferencial de mercado, pois sinaliza reconhecimento social de que a instituição melhora continuamente a qualidade de seus serviços (BONATO, 2007; PERTENCE; MELLEIRO, 2010; JOINT COMMISSION, 2011). Apesar do propósito comum do movimento internacional de Acreditação, cada programa foi localmente adaptado às realidades nacionais. Assim, esse processo pode variar conforme a cultura e as políticas hospitalares nacionais (COUTO; PEDROSA, 2007).

O pioneiro na adoção do processo de Acreditação foi os Estados Unidos, onde a Acreditação é coordenada pela Joint Commission on Accreditation of Healthcare Organizations (JCAHO) (ANTUNES; RIBEIRO, 2005; FELDMAN; GATTO; CUNHA, 2005; D'INNOCENZO; ADAMI; CUNHA, 2006; BONATO, 2007). Atualmente, $85 \%$ dos hospitais norteamericanos são Acreditados (JOINT COMMISSION, 2011). O processo de Acreditação da Joint Commission (JC) inspirou o surgimento de outros programas de Acreditação, entre os quais, o brasileiro (GURGEL JUNIOR; VIEIRA, 2002; ANTUNES; RIBEIRO, 2005; FELDMAN; GATTO; CUNHA, 2005; COUTO; PEDROSA, 2007).

No Brasil, a Acreditação é voluntária e coordenada pela ONA (Organização Nacional de Acreditação), Organização não governamental que busca conceder o certificado de Acreditação, classificando os hospitais em três níveis, conforme o cumprimento de padrões do Manual Brasileiro de Acreditação (ANTUNES; RIBEIRO, 2005; FELDMAN; GATTO; CUNHA, 2005; BONATO, 2007; ORGANIZAÇÃO..., 2010). Os níveis de classificação são crescentes e envolvem requisitos de Estrutura (Nível 1: Acreditado), Processos (Nível 2: Acreditação Plena) e Resultados (Nível 3: Acreditação por Excelência) (ORGANIZAÇÃO..., 2010) .

A Acreditação brasileira é incipiente (em 2012, 2,4\% dos hospitais brasileiros eram Acreditados), havendo carência de uma orientação que direcione hospitais brasileiros interessados em obter a Acreditação (ORGANIZAÇÃO..., 2011), principalmente os de menor porte e com carências de gestão e de recursos. $\mathrm{O}$ artigo propõe um roteiro para implantação dos requisitos de Acreditação da ONA para auxiliar gestores hospitalares interessados nesta certificação.

A primeira versão do roteiro proposto baseou-se em uma pesquisa exploratória realizada em três hospitais Acreditados e em revisão bibliográfica sobre processo de implantação de Sistemas de Gestão da Qualidade (SGQ) em hospitais. A versão preliminar desse roteiro foi testada em uma pesquisa-ação em um hospital de pequeno porte, visando a implantação dos requisitos de Acreditação. Assim, foi possível testar e aperfeiçoar o roteiro. Depois do término da pesquisa ação, o roteiro foi revisado e é apresentado no final deste artigo.

\section{Implantação de Sistemas de Gestão da Qualidade (SGQ) em hospitais}

A implantação da Gestão da Qualidade em hospitais requer o comprometimento da Alta Administração quanto às mudanças necessárias para tal iniciativa, pois são necessários esforços constantes para incorporar, em toda a equipe e níveis hierárquicos, os conceitos da busca de melhoria contínua (OVRETVEIT; GUSTAFSON, 2002; MACINATI, 2008).

Um SGQ envolve mudanças tecnológica, filosófica, cultural e na governança do hospital. A mudança tecnológica e de filosofia são alterações nas formas de execução do trabalho em termos de procedimentos, rotinas e normas do serviço prestado aos pacientes. A mudança cultural são alterações na cultura organizacional em termos de padrões, valores e crenças sobre como funciona a Organização. A mudança no sistema de governança do hospital se dá no processo de tomada de decisão e estrutura de poder. Essas mudanças devem estar alinhadas (SATIA; DOHLIE, 1999; PFEIFER, 2002; FRANÇOIS; POMEY, 2005).

Uma estratégia de promoção da Gestão da Qualidade focada na educação e treinamento em seus conceitos e valores é importante para disseminar novas culturas e paradigmas. Essa disseminação deve se iniciar na Alta Administração do hospital até chegar aos níveis mais operacionais. Educação e treinamento devem ocorrer com todos os profissionais do hospital. Essa gestão deve ser conduzida por um Comitê ou departamento voltado para a Gestão da Qualidade. O SGQ deve ser apoiado pela implantação de indicadores de desempenho apropriados (KUBALLA, 2007; KLUCK et al., 2008).

A implantação malsucedida de um SGQ não se deve a diferenças nos conceitos e culturas dos hospitais, mas à adoção de uma estratégia de implantação inapropriada. Não existe uma forma única de iniciar a implantação de um SGQ em instituições hospitalares, pois a implantação deverá refletir as peculiaridades de cada caso (WARDHANI et al., 2009).

Há duas formas de iniciar o processo de implantação de tais Sistemas em hospitais: por Gerenciamento por Diretrizes ou por Gerenciamento da Rotina. A primeira prevê o estabelecimento de uma meta de sobrevivência para que sejam gerados planos de ação específicos em cada setor, atingindo todos os níveis da Organização. O Gerenciamento por Diretrizes alinha os esforços de cada setor e o comprometimento de todos para com a meta proposta pela Alta Administração, possibilitando a articulação dos esforços de todos e a coordenação das ações. Já o Gerenciamento da 
Rotina foca a padronização dos processos obtida pelo estabelecimento de fluxogramas e de procedimentos de atividades consideradas prioritárias em cada setor e do monitoramento de indicadores. É eficiente para conhecer o desempenho atual e assegurar a previsibilidade dos desvios nos resultados, em comparação com as metas (PFEIFER, 2002; BONATO, 2007; NOGUEIRA, 2008).

Wardhani et al. (2009) recomendam como estratégias para um SGQ bem-sucedido:

- Iniciar a implantação de ações de Gestão da Qualidade em alguns departamentos para, a seguir, disseminá-las a todos. Isso reduz riscos e tornam possíveis melhorias internas em curto prazo, gerando maior aceitação por parte dos outros departamentos do hospital;

- Iniciar a implantação das ações no hospital como um todo. Tal estratégia é iniciada pela conscientização e pela preparação da estrutura hospitalar para a Gestão da Qualidade.

Satia e Dohlie (1999) recomendam sete condições para implantação bem-sucedida de SGQ em hospitais:

- Sensibilizar a Alta Administração do hospital, obtendo o comprometimento desta para a importância de participar e apoiar as ações de implantação do SGQ;

- Nomear um Comitê de Implantação contendo profissionais de diferentes áreas;

- Realizar palestras e treinamento contínuo que envolvam todos os profissionais do hospital, desde o front line até a Alta Administração;

- Documentar a padronização dos procedimentos e criar uma sistemática de medição dos processos do hospital, monitorando-os;

- Ter a participação dos clientes externos do hospital no processo de implantação, envolvendo-os em reuniões e discussões sobre o SGQ e obtendo suas sugestões;

- Incentivar a participação e o envolvimento de todos os profissionais, por meio de premiações não necessariamente financeiras;

- Fornecer os recursos, equipamentos e materiais necessários à implantação do SGQ.

As estratégias apresentadas por vários autores têm em comum a reafirmação de fatores fundamentais à implantação de um SGQ eficiente:

- Comprometimento da Alta Administração com o processo de implantação do SGQ, fornecendo os recursos necessários;

- Conscientização e envolvimento de todos os profissionais no processo de implantação, inclusive, nomeando um Comitê de Implantação contendo profissionais e diferentes áreas da instituição;

- Conscientização de que o retorno financeiro da implantação é de longo prazo.

Portanto, observam-se diversos fatores a serem equacionados para a implantação de um SGQ hospitalar. Sua reunião harmoniosa pela Alta Administração é um passo inicial e essencial ao sucesso da implantação.

\section{Método de pesquisa}

A pesquisa de campo foi desenvolvida com base em dois métodos:

- Estudo de múltiplos casos com finalidade exploratória para obter conhecimento sobre o tema de pesquisa e subsidiar a realização da fase seguinte da pesquisa;

- Pesquisa-ação conduzida em um hospital público de pequeno porte.

Ambos os métodos foram planejados como complementares e aplicados nesta sequência. Assim, a pesquisa de campo completa foi desenvolvida nas seguintes fases:

Fase 1: pesquisa bibliográfica sobre implantação de SGQ e da Acreditação hospitalar. Os conhecimentos obtidos nesta revisão subsidiaram a elaboração de um roteiro de entrevistas para a realização dos estudos de casos.

Fase 2: estudo de casos em três hospitais Acreditados há, pelo menos, 4 anos sobre o processo de implantação da Acreditação. O roteiro de entrevistas foi aplicado junto ao Gerente da Qualidade desses hospitais. Os casos geraram mais aprendizagem sobre o tema e permitiram obter informações sobre o processo de implantação da Acreditação nesses hospitais.

Essa aprendizagem obtida com os estudos de casos, aliada à pesquisa bibliográfica sobre a implantação da Acreditação, subsidiou a realização da pesquisa-ação.

Fase 3: elaboração de um roteiro preliminar de implantação da Acreditação, o qual subsidiou a condução da pesquisa-ação.

Fase 4: condução da pesquisa-ação para adequação da gestão de um hospital público de pequeno porte aos requisitos de Acreditação.

A pesquisa-ação seguiu o modelo de Coughlan e Coghlan (2002) que tem como etapas: Etapa Preliminar, Tratamento de Dados, Plano de Ação, Avaliação e Monitoramento dos Resultados.

Fase 5: revisão e ajuste no roteiro de implantação. O conhecimento obtido na pesquisa-ação permitiu gerar a versão proposta no roteiro para implantação dos requisitos de Acreditação. 


\section{Pesquisa exploratória}

\subsection{Adequação da gestão do Hospital B aos requisitos de Acreditação}

O Hospital B é de grande porte, foi fundado em 2003 e possui 318 leitos. Oferece serviços de atendimento ambulatorial, centro cirúrgico, UTI, Emergência, Banco de Sangue, etc. É Acreditado desde novembro de 2004, possuindo o certificado de Acreditação Plena, obtido em 2006 e revalidado em outubro de 2010.

O processo de adequação iniciou-se em novembro de 2003, quando a Alta Administração trouxe gestores de outro Hospital Acreditado para realização de palestras de conscientização e mobilização ao processo de Acreditação, suas etapas e benefícios.

Uma Comissão de seis profissionais (o Diretor Técnico, um enfermeiro, um farmacêutico, dois médicos e um profissional do setor Administrativo) foi nomeada para conduzir e monitorar as ações de adequação da gestão do Hospital. Estes profissionais foram submetidos ao curso de capacitação para Acreditação ministrado pela ONA e, posteriormente, iniciaram a estruturação do Escritório da Qualidade.

A Comissão realizou um diagnóstico das necessidades de adequação da gestão aos requisitos de Acreditação. Como o hospital era recém-inaugurado, foram necessárias diversas adequações. Não havia Gestão da Qualidade estruturada, Processos mapeados, Indicadores de processos, Gestão de Risco. A documentação de procedimentos estava em elaboração.

Neste hospital, foram apontados como facilitadores ao processo de adequação: instalações e equipamentos modernos e compatíveis à demanda atendida; ofereciam-se, na época, apenas serviços de atendimento emergencial e ambulatorial; a Alta Administração se envolveu no processo desde o início, sendo responsável pela ideia de implantá-lo participando, ativamente, das ações e reuniões das fases de adequação e de pós-adequação.

Na fase de pré-implantação, a principal dificuldade foi capacitar os profissionais do Escritório da Qualidade nos conceitos da Acreditação, fazendo-os compreender os requisitos da ONA. Na fase de adequação da gestão, a principal dificuldade foi a falta de mobilização e conscientização dos profissionais quanto às ações implementadas e a falta de aplicação dessas ações na rotina de trabalho. O maior foco de resistência foi a equipe médica, que relutou em aplicar as adequações à sua rotina de trabalho e em participar da Comissão de Implantação.

Para superar tais dificuldades, o Escritório da Qualidade recorreu à capacitação rotineira dos profissionais do hospital, por meio de palestras explicativas sobre GQ na Saúde, Acreditação e ferramentas da Qualidade. A mobilização e a aplicação dos conceitos e ações à rotina de trabalho foram incentivadas pela distribuição de bótons, balas com mensagens de incentivo e boletins informativos das iniciativas de adequação que estavam ocorrendo.

Mensalmente, são realizadas reuniões de análise crítica das ações e dos resultados do SGQ e da Melhoria Contínua, com a participação da Alta Administração, do Escritório da Qualidade e dos chefes de setor. Os setores com os melhores resultados do mês são premiados com aumento financeiro no vale-refeição.

Para a condução do processo de adequação à Acreditação, o Gerente da Qualidade recomendou identificar e documentar os macroprocessos e suas interações, iniciar as adequações pelos macroprocessos críticos, desdobrar os macroprocessos em microprocessos e em atividades, iniciando pelos macroprocessos críticos; realizar, continuamente, a divulgação das adequações e suas ações em palestras, cartazes e vídeos para que os profissionais tenham a real dimensão do que está acontecendo e sintam-se motivados a se envolver.

\subsection{Adequação da gestão do Hospital C aos requisitos de Acreditação}

O Hospital C é de grande porte e possui 803 leitos. Oferece os serviços de atendimento ambulatorial, Centro Cirúrgico, UTI, Emergência, Banco de Sangue, Maternidade, Obstetrícia, etc. É Acreditado Pleno desde 2007 e atualmente é Acreditado por Excelência, desde 2008.

$\mathrm{O}$ processo de adequação aos requisitos de Acreditação foi facilitado pelo prévio histórico de certificações do hospital, como a ISO 9001, obtida em 1999. No final de 2006, quando a decisão de adesão à Acreditação foi tomada, o hospital já possuía um Departamento da Qualidade estruturado e atuante, desde 1992, e as práticas de GQ já estavam consolidadas.

No início de 2007, foi realizado, por uma Agência Acreditadora, um diagnóstico das necessidades de adequação da gestão aos requisitos de Acreditação. Os requisitos de Acreditação Plena e de Acreditação por Excelência já eram contemplados pela gestão do hospital. Para adaptar e conscientizar seus profissionais sobre as práticas e conceitos da Acreditação, optou-se por aderir à Acreditação Plena. Posteriormente, foram realizadas palestras explicativas semanais e reportagens publicadas no jornal interno e nos murais informativos. A equipe do Departamento da Qualidade foi capacitada em cursos de auditores internos da ONA. Um ano depois, em 2008, foi obtida a Acreditação por Excelência.

Os chefes de setor são capacitados e têm autonomia para solucionar problemas sem recorrer ao Departamento da Qualidade. Em caso de problemas 
graves, os chefes entram em contato com o Gerente da Qualidade para definição conjunta da solução. Mensalmente, ocorrem reuniões de análise crítica das quais participam a equipe da Qualidade, os chefes de setor e outros dois profissionais (um representante dos profissionais, eleito pelos mesmos profissionais e outro representante dos serviços de apoio).

Nessas reuniões, os chefes de setor apresentam os resultados do mês, os problemas ocorridos, as soluções implantadas e as ações de melhoria implantadas e em implantação. As iniciativas de melhoria são avaliadas com base nos indicadores de desempenho financeiros (Custos por paciente internado, Receitas, Lucro Líquido, etc.), assistenciais (Incidência de Extubação Acidental, Incidência de Brônquio-Aspiração, Perda de Sonda Vesical, etc.) e setoriais (perda de filme de raios $\mathrm{X}$, erros na prescrição da dieta nutricional do paciente, incidência de ingestas nutricionais, taxa de erros em prontuários, etc.)

As perspectivas quanto à Acreditação são iniciar e integrar o Programa Lean-Sigma, tido pela Alta Administração como uma forma de inovação e vanguarda no setor hospitalar.

Para condução da adequação da gestão à Acreditação, o Gerente da Qualidade recomendou apoio e participação da Alta Administração, divulgação das ações de adequação em murais e jornais informativos, realização contínua de palestras explicativas com os profissionais para melhor compreensão dos conceitos da Acreditação e as melhorias proporcionadas à rotina de trabalho; mapeamento dos processos do hospital com a participação de profissionais dos setores, podendo ser realizado em reuniões de brainstorming, formação de uma Comissão para conduzir as etapas de adequação da gestão.

\subsection{Adequação da gestão do Hospital D aos requisitos de Acreditação}

Fundado em 2003, o Hospital D situa-se no interior do Estado de São Paulo, e tem 80 leitos, sendo considerado de médio porte. Oferece os serviços de atendimento ambulatorial, centro cirúrgico, UTI, Emergência, Banco de Sangue, Maternidade, etc. É Acreditado desde 2005 e atualmente possui Acreditação Plena, obtida em 2007 e mantida em 2009.

A decisão de aderir à Acreditação partiu da Alta Administração logo nos primeiros meses de fundação, visando iniciar a gestão segundo os valores da Acreditação. Assim, outro hospital já Acreditado foi contratado para realizar palestras de conscientização e mobilização para o processo de Acreditação, suas etapas e benefícios.

Para conduzir e monitorar as ações de adequação, formou-se uma Comissão de seis profissionais (Diretor Técnico, Chefe de Enfermagem, Chefe Administrativo, Chefe de Recursos Humanos, um Médico e Engenheiro de Segurança do Trabalho). A Comissão foi capacitada para auditoria interna de Acreditação e estruturou o Escritório da Qualidade.

Posteriormente, foi realizado um Diagnóstico para identificar os requisitos de Acreditação não contemplados. Como o hospital era recém-inaugurado, foram necessárias diversas adequações. Não havia Gestão da Qualidade estruturada (o Escritório da Qualidade havia sido definido recentemente), processos mapeados, indicadores de processos, Gestão de Risco. A documentação de procedimentos estava em fase de elaboração.

Os facilitadores da adequação foram instalações e equipamentos compatíveis à demanda atendida; a Alta Administração esteve envolvida no processo desde o início, participando ativamente das ações e reuniões das fases de adequação e pós-adequação; os membros do Escritório da Qualidade foram capacitados para Acreditação em cursos ministrados pela ONA.

A principal dificuldade do processo de adequação foi a resistência dos profissionais a adotarem as práticas e as mudanças propostas à rotina de trabalho, em consequência da falta de compreensão e conscientização. O principal foco de resistência foram enfermeiros e médicos. Os médicos relutaram em adotar as práticas implantadas com a Acreditação e em participar da Comissão de Adequação. A equipe de enfermagem resistiu em notificar a ocorrência de erros e eventos adversos, temendo uma atitude punitiva da Alta Administração.

Tais resistências foram superadas com a capacitação desses profissionais, a administração de palestras sobre Acreditação, GQ e Gestão de Risco, e de estímulos junto aos enfermeiros para notificação voluntária de erros e eventos adversos, distribuindo-se prêmios não financeiros ao profissional que realizasse o maior número mensal de notificações.

Outro incentivo ao envolvimento dos profissionais no processo de adequação ocorreu na fase de documentação dos procedimentos. Esta teve a participação de todos os profissionais em reuniões de brainstorming. Nestas, o profissional que realizasse contribuições valiosas ao procedimento era homenageado com a colocação de seu nome no procedimento.

O Hospital D planeja obter a Acreditação por Excelência em 2012. Para tal, introduziu-se o FMEA (Failure Mode and Effect Analysis) para prevenção de falhas nos serviços, o que é tido pela Alta Administração como uma ação inovadora no setor.

Para a condução da adequação da gestão à Acreditação, o Gerente da Qualidade recomendou identificar o Perfil Epidemiológico do hospital; identificar e documentar os macroprocessos e suas interações; realizar brainstorming com os profissionais dos setores para elaborar e definir as ações a serem implantadas, fazendo-os participar do mapeamento dos 
processos e de riscos e da elaboração de procedimentos documentados; recorrer ao auxílio de Hospitais Acreditados em caso de dúvidas no processo.

\subsection{Síntese da pesquisa exploratória}

A partir das informações coletadas e das observações nas entrevistas conduzidas nos três Hospitais B, C, e D, foi possível constatar, durante os processos de adequação da gestão aos requisitos da ONA, que: não houve necessidade de consultoria externa para coordenar o processo; o processo foi conduzido internamente, por meio da nomeação de uma Comissão de membros capacitados em curso de Acreditação ministrado pela ONA.

As principais dificuldades foram a falta de compreensão e conscientização dos profissionais quanto aos conceitos e práticas da Acreditação, bem como a resistência de médicos e enfermeiros a adotar os procedimentos em suas rotinas de trabalho.

As principais recomendações identificadas pelos Gerentes da Qualidade dos três hospitais como sendo relevantes à condução do processo de adequação da gestão hospitalar aos requisitos de Acreditação Plena foram: formar uma Comissão interna com profissionais para implementar o processo; identificar e documentar os macroprocessos e o fluxo entre eles; identificar os processos críticos do hospital, priorizando-os; consultar hospitais acreditados, em caso de dúvidas durante o processo; realizar, continuamente, palestras explicativas para informar e conscientizar os profissionais do hospital sobre o processos e as ações implantadas; adotar uma sistemática de incentivo ao envolvimento dos profissionais no processo com premiações, participação em reuniões de brainstorming e de análise crítica.

\section{Roteiro preliminar para implantação da Acreditação Hospitalar}

A partir da pesquisa exploratória e da revisão bibliográfica, elaborou-se um Roteiro Preliminar de Implantação da Acreditação em hospitais, expresso na Figura 1 e descrito no Quadro 2. Na revisão bibliográfica, realizou-se um levantamento de trabalhos que propõem etapas de implantação de diferentes tipos de Sistemas, como TQM (Total Quality Management), SGQ, ISO 9001. Alguns desses trabalhos estão no Quadro 1. Aplicou-se o Roteiro Preliminar em uma pesquisa-ação no Hospital A, em que se buscou adequar a gestão aos requisitos de Acreditação, permitindo validação, teste e aprimoramento do roteiro.

\section{A pesquisa-ação realizada no Hospital A}

Inaugurado em 2007, o Hospital A situa-se no interior de São Paulo, tendo 32 leitos (pequeno porte). Disponibiliza serviços de atendimento ambulatorial, pronto-atendimento e diagnóstico por imagem (raios X, mamografia e tomografia). Dispõe de 67 profissionais (médicos, enfermeiros, fisioterapeutas, psicólogos, etc.). Em 2013, serão disponibilizados os serviços de UTI e Centro Cirúrgico, elevando o número de leitos oferecidos para 188 .

Esta seção descreve as etapas da pesquisa-ação, segundo o modelo de Coughlan e Coghlan (2002), realizada neste Hospital a fim de adequar sua gestão aos requisitos de Acreditação da ONA.

\subsection{Etapa preliminar}

A Etapa Preliminar teve início com a realização de reuniões envolvendo o pesquisador e a Alta Administração do hospital. Nessas reuniões, foram explicitados os propósitos da pesquisa-ação, as condições necessárias à sua realização e seu objetivo principal: planejar e implantar uma sistemática de gestão compatível com os requisitos de Acreditação.

Definiu-se que o pesquisador estaria imerso no ambiente hospitalar diariamente, em turnos alternados, para observar a rotina de trabalho dos profissionais e as necessidades de adequação da gestão. Formou-se um Comitê de Acreditação com profissionais do hospital que seria continuamente informado das ações realizadas pela pesquisa-ação e participaria da tomada de decisão, do planejamento, implementação e monitoramento de cada ação.

Para o Comitê, foram designados dezesseis profissionais com características de liderança de diferentes setores do hospital. Os membros do Comitê deveriam atuar, nos setores, como multiplicadores das ações e conceitos inseridos pela pesquisa-ação. Entre os membros do Comitê estavam: Diretor Técnico; Chefe de Enfermagem; Chefe Administrativo; dois médicos; três enfermeiros; Chefe da Farmácia; etc.

Para divulgar a pesquisa-ação, disseminar seus fundamentos e propósitos, realizaram-se, no primeiro mês, palestras com todos os profissionais do hospital.

\subsection{Coleta de dados}

Para identificar as necessidades de adequação da gestão, consultaram-se registros e documentos formais como: registros de indicadores de desempenho; atas de reuniões; cronogramas; procedimentos documentados; escalas dos profissionais; notificações de eventos adversos; registros dos programas de capacitação ministrados; etc.

Entrevistas informais com profissionais de cada setor ocorreram durante o expediente de trabalho e 
Etapa 1: Conscientizar e Mobilizar os profissionais do hospital quanto à implantação dos requisitos de Acreditação

Etapa 2: Formar e Capacitar Comitê de condução da Adequação da gestão aos requisitos de Acreditação

\begin{tabular}{|c|}
\hline $\begin{array}{c}\text { Etapa 3: Capacitar e Educar os profissionais do hospital quanto } \\
\text { aos conceitos, valores, requisitos e diretrizes da Acreditação }\end{array}$ \\
\hline Etapa 4: Buscar a Motivação e o Envolvimento dos profissionais para o processo de implantação da \\
Acreditação
\end{tabular}

Etapa 5: Iniciar a Adequação da Gestão aos requisitos de Acreditação da ONA

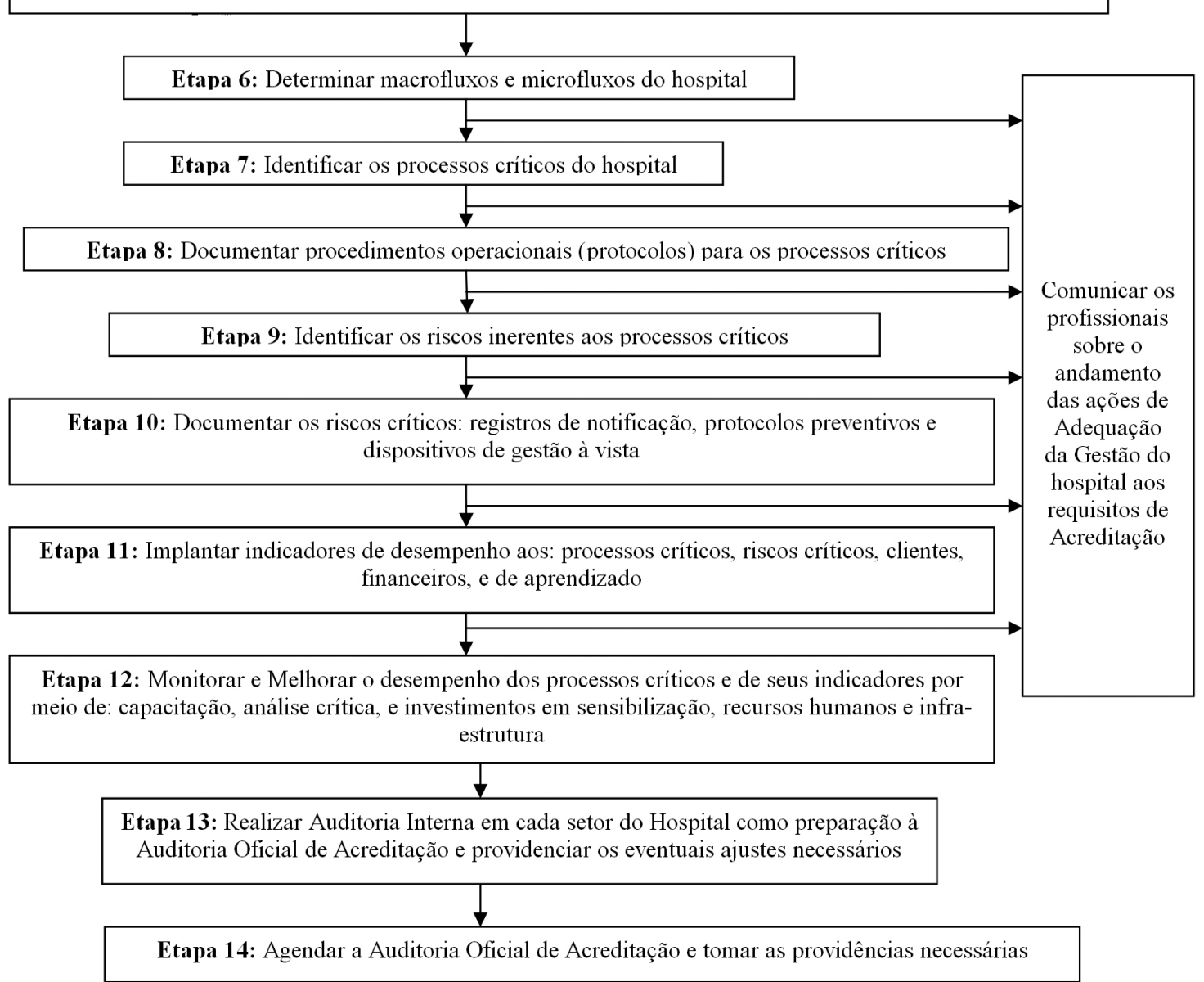

Figura 1. Roteiro Preliminar para implantação dos requisitos de Acreditação.

possibilitaram a obtenção de informações sobre a compatibilidade entre a equipe de enfermagem, a demanda atendida e a estrutura disponível para os atendimentos.

\subsection{Disponibilização dos dados}

Foram realizadas reuniões e palestras com o Comitê, para discutir os dados coletados e facilitar discussões sobre melhorias, registros, documentações e ações a serem implantadas, além de refletir sobre as necessidades de adequação da gestão aos requisitos de Acreditação. Identificaram-se 48 oportunidades de melhoria na gestão do hospital, sendo as principais:

- Processos não identificados e não documentados;

- Fluxos dos processos não identificados e não documentados;

- Procedimentos não documentados e não padronizados; 
Quadro 1. Autores e trabalhos de referência para proposição do Roteiro Preliminar.

\begin{tabular}{|c|c|c|}
\hline Autores & Título do Trabalho & Tema de Enfoque do Trabalho \\
\hline Schyve (1995) & $\begin{array}{l}\text { Models for relating performance } \\
\text { measurement and accreditation }\end{array}$ & $\begin{array}{l}\text { Modelos de medicação do desempenho da } \\
\text { gestão hospitalar }\end{array}$ \\
\hline Torelli e Ferreira (1995) & $\begin{array}{l}\text { Qualidade Total: proposta de um modelo } \\
\text { para implantação }\end{array}$ & $\begin{array}{c}\text { Processo de implantação do TQM em uma } \\
\text { empresa de manutenção de aeronaves }\end{array}$ \\
\hline Oliveira (1998) & $\begin{array}{c}\text { A vivência da implantação do programa de } \\
\text { Qualidade Total: um estudo de caso }\end{array}$ & $\begin{array}{c}\text { Processo de implantação do TQM em uma } \\
\text { empresa têxtil }\end{array}$ \\
\hline Satia e Dohlie (1999) & $\begin{array}{c}\text { Achieving Total Quality Management in } \\
\text { Public Health System }\end{array}$ & $\begin{array}{c}\text { Processo de implantação do TQM em } \\
\text { hospitais da Malásia }\end{array}$ \\
\hline François e Pomey (2005) & $\begin{array}{c}\text { Implantation de la gestion de la qualité } \\
\text { dans le hopitaux français, jeux d'acteurs } \\
\text { et transformations induites }\end{array}$ & $\begin{array}{l}\text { Análise de métodos de implantação de } \\
\text { SGQ em hospitais da França }\end{array}$ \\
\hline $\begin{array}{l}\text { Correia, Melo e Medeiros } \\
\text { (2006) }\end{array}$ & $\begin{array}{l}\text { Modelo de diagnóstico e implementação } \\
\text { de um sistema de gestão da qualidade }\end{array}$ & $\begin{array}{c}\text { Método para implantação de um SGQ em } \\
\text { uma siderúrgica }\end{array}$ \\
\hline $\begin{array}{l}\text { Tachizawa e Scaico } \\
\text { (2006) }\end{array}$ & Qualidade na Gestão por Processos & $\begin{array}{l}\text { Etapas para padronização de processos de } \\
\text { SGQ }\end{array}$ \\
\hline $\begin{array}{l}\text { François, Boyer e Weil } \\
\qquad(2008)\end{array}$ & $\begin{array}{l}\text { Implantation of quality management } \\
\text { in medical departments of a teaching } \\
\text { hospital: Accelerators and inhibitors }\end{array}$ & $\begin{array}{l}\text { Processo de implantação de um SGQ em } \\
\text { um hospital universitário, destacando } \\
\text { fatores facilitadores e dificultadores }\end{array}$ \\
\hline Nogueira (2008) & $\begin{array}{c}\text { Gerenciando pela Qualidade Total na } \\
\text { Saúde }\end{array}$ & $\begin{array}{l}\text { Processo de implantação do TQM em } \\
\text { hospitais }\end{array}$ \\
\hline Vitner et al. (2010) & ISO 9001 in a neonatal intensive care unit & $\begin{array}{c}\text { Processo de implantação de ISO } 9001 \mathrm{em} \\
\text { uma UTI neonatal }\end{array}$ \\
\hline
\end{tabular}

- Gestão de riscos inexistente;

- Inexistência de indicadores de desempenho dos processos.

As 48 oportunidades foram disseminadas, pelo Comitê aos setores do hospital. As iniciativas da pesquisa-ação eram comunicadas a todos os profissionais, para que pudessem participar e propor soluções para as oportunidades de melhoria levantadas.

Na Etapa de Análise dos Dados, foram definidas as primeiras iniciativas a serem implementadas: determinação dos processos críticos; elaboração do mapeamento dos macrofluxos desses processos; e documentação dos procedimentos operacionais.

\subsection{Plano de ação}

As oportunidades de melhoria resultaram em três Planos de Ação. O Comitê analisou-os, criticamente, aprovou-os, validou-os, definiu prazos, responsáveis e adequou-os à realidade dos processos e recursos do hospital. Os três Planos de Ação são: Mapeamento, Análise e Melhoria de Processos e Procedimentos; Mapeamento, Análise e Tratamento de Riscos e Eventos Adversos; e Concepção e Implantação de Indicadores de Desempenho.

\subsubsection{Plano de Ação I: mapeamento, análise e melhoria de processos e procedimentos}

\subsubsection{Determinação e mapeamento dos macroprocessos críticos}

A implantação do Plano I iniciou-se pelo mapeamento dos macroprocessos, os quais foram identificados em reuniões entre a Alta Administração e o Comitê de Acreditação. Foram identificados dez macroprocessos e seus fluxos constam da Figura 2.

Diagnóstico, Tratamento e Saída foram considerados críticos para a assistência prestada por se tratar de processos finalísticos (relacionados diretamente ao tratamento dos pacientes). $\mathrm{O}$ macroprocesso Tratamento é constituído por microprocessos relativos a todas as formas de tratamento clínico e fisioterápico. Seus fornecedores são: a farmácia, a emergência, a internação e a assistência psicológica. Os microprocessos de Tratamento são: Consulta Médica, Assistência de Farmácia e Assistência de Enfermagem.

O macroprocesso Diagnóstico depende de microprocessos ligados ao laboratório de microbiologia, à radiologia, à ultrassonografia e à tomografia, e à proficiência dos médicos e enfermeiros 
Quadro 2. Descrição das Etapas de Implantação dos requisitos de Acreditação.

\begin{tabular}{|c|c|c|}
\hline $\begin{array}{c}\text { Etapas de } \\
\text { implantação }\end{array}$ & Tarefas da Etapa & Descrição da Tarefa \\
\hline Etapa 1 & $\begin{array}{l}\text { Conscientizar e Mobilizar os profissionais do } \\
\text { hospital quanto à implantação dos requisitos de } \\
\text { Acreditação }\end{array}$ & $\begin{array}{l}\text { A Alta Administração deve iniciar o processo } \\
\text { de conscientização e mobilização dos } \\
\text { profissionais do hospital para o processo de } \\
\text { implantação da Acreditação a ser realizado. } \\
\text { Para tal, pode-se realizar palestras, reuniões, } \\
\text { visitas aos setores; trazer profissionais de } \\
\text { hospitais Acreditados para que estes realizem } \\
\text { palestras para os profissionais, etc. A etapa } \\
1 \text { busca evidenciar a participação da Alta } \\
\text { Administração no processo de implantação. }\end{array}$ \\
\hline Etapa 2 & $\begin{array}{l}\text { Formar e Capacitar Comitê de condução } \\
\text { da Adequação da gestão aos requisitos de } \\
\text { Acreditação }\end{array}$ & $\begin{array}{l}\text { Um comitê para conduzir a implantação dos } \\
\text { requisitos de Acreditação deve ser formado, } \\
\text { contendo membros da Alta Administração e } \\
\text { chefes de setores do hospital. }\end{array}$ \\
\hline Etapa 3 & $\begin{array}{l}\text { Capacitar e Educar os profissionais do hospital } \\
\text { quanto aos conceitos, valores, requisitos e } \\
\text { diretrizes da Acreditação }\end{array}$ & $\begin{array}{l}\text { O Comitê deve promover a capacitação e a } \\
\text { educação dos profissionais do hospital em } \\
\text { relação aos conceitos, requisitos e diretrizes } \\
\text { da Acreditação, por meio de palestras, vídeos } \\
\text { explicativos, palestras com profissionais de } \\
\text { hospitais Acreditados, etc. }\end{array}$ \\
\hline Etapa 4 & $\begin{array}{l}\text { Buscar a Motivação e o Envolvimento dos } \\
\text { profissionais do hospital para com o processo } \\
\text { de implantação da Acreditação }\end{array}$ & $\begin{array}{l}\text { Deve-se buscar o envolvimento e a motivação } \\
\text { dos profissionais do hospital ao processo de } \\
\text { implantação dos requisitos de Acreditação por } \\
\text { meio de cartazes, mensagens de incentivos } \\
\text { em cada setor, premiações, reuniões de } \\
\text { brainstorming e promovendo a participação de } \\
\text { profissionais de cada setor em reuniões sobre } \\
\text { as ações futuras e em andamento do processo. }\end{array}$ \\
\hline \multirow[t]{2}{*}{ Etapa 5} & $\begin{array}{l}\text { Iniciar a Adequação da Gestão aos requisitos } \\
\text { de Acreditação da ONA }\end{array}$ & $\begin{array}{l}\text { Refere-se ao início das ações de Adequação da } \\
\text { gestão aos requisitos de Acreditação. }\end{array}$ \\
\hline & $\begin{array}{l}\text { Comunicar aos profissionais o andamento das } \\
\text { ações de Adequação da Gestão do hospital aos } \\
\text { requisitos de Acreditação }\end{array}$ & $\begin{array}{l}\text { No decorrer do processo de Adequação, } \\
\text { as ações de implantação devem ser, } \\
\text { continuamente, comunicadas pelo Comitê } \\
\text { aos profissionais. Isso pode ocorrer por meio } \\
\text { de reuniões, boletins informativos, notícias } \\
\text { em jornais internos, palestras, etc. A Alta } \\
\text { Administração deve participar de tais reuniões } \\
\text { e palestras, evidenciando seu envolvimento no } \\
\text { processo. }\end{array}$ \\
\hline Etapa 6 & $\begin{array}{l}\text { Determinar macrofluxos e microfluxos do } \\
\text { Hospital }\end{array}$ & $\begin{array}{l}\text { Identificar, em registros e mapas, o fluxo } \\
\text { seguido pelos atendimentos e o relacionamento } \\
\text { entre todos os processos do Hospital. }\end{array}$ \\
\hline Etapa 7 & Identificar os processos críticos do Hospital & $\begin{array}{l}\text { Identificar, entre os processos mapeados, } \\
\text { aqueles que críticos ao Hospital. }\end{array}$ \\
\hline Etapa 8 & $\begin{array}{l}\text { Documentar procedimentos operacionais } \\
\text { (protocolos) para os processos críticos }\end{array}$ & $\begin{array}{l}\text { Elaborar procedimentos operacionais } \\
\text { (protocolos) associados aos processos críticos. }\end{array}$ \\
\hline Etapa 9 & $\begin{array}{l}\text { Identificar os riscos inerentes aos processos } \\
\text { críticos }\end{array}$ & $\begin{array}{l}\text { Identificar os riscos (ambientais, assistenciais, } \\
\text { profissionais, clínicos, etc.), documentando-os. }\end{array}$ \\
\hline Etapa 10 & $\begin{array}{l}\text { Documentar os riscos críticos: registros } \\
\text { de notificação, protocolos preventivos e } \\
\text { dispositivos de gestão à vista }\end{array}$ & $\begin{array}{l}\text { Identificar os riscos mais críticos aos } \\
\text { processos mapeados, documentando-os para } \\
\text { monitoramento e melhoria. }\end{array}$ \\
\hline
\end{tabular}


Quadro 2. Continuação...

\begin{tabular}{|l|l|l|}
\hline \multicolumn{1}{|c|}{$\begin{array}{c}\text { Etapas de } \\
\text { implantação }\end{array}$} & \multicolumn{1}{|c|}{ Tarefas da Etapa } & \multicolumn{1}{c|}{ Descrição da Tarefa } \\
\hline Etapa 11 & $\begin{array}{l}\text { Implantar indicadores de desempenho aos } \\
\text { processos críticos, riscos críticos, clientes, } \\
\text { financeiros e de aprendizado }\end{array}$ & $\begin{array}{l}\text { As atividades da sistemática de Gestão } \\
\text { recém-implantada devem ser monitoradas } \\
\text { por meio de indicadores que devem ter o } \\
\text { desempenho analisado e melhorado (Gestão } \\
\text { por Evidências). }\end{array}$ \\
\hline Etapa 12 & $\begin{array}{l}\text { Monitorar e Melhorar o desempenho dos } \\
\text { processos críticos e de seus indicadores } \\
\text { por meio de: capacitação, análise crítica, e } \\
\text { investimentos em sensibilização, recursos } \\
\text { humanos e infraestrutura }\end{array}$ & $\begin{array}{l}\text { Realizar o monitoramento periódico dos } \\
\text { indicadores para avaliação do desempenho } \\
\text { das práticas de gestão implementadas nas } \\
\text { etapas anteriores. Melhorar continuamente as } \\
\text { atividades. }\end{array}$ \\
\hline Etapa 13 & $\begin{array}{l}\text { Realizar Auditoria Interna em cada setor do } \\
\text { Hospital como preparação à Auditoria Oficial } \\
\text { de Acreditação e providenciar os eventuais } \\
\text { ajustes necessários }\end{array}$ & $\begin{array}{l}\text { Realizar, em cada setor do Hospital, uma } \\
\text { Auditoria Interna, checando e repassando o } \\
\text { cumprimento de cada requisito avaliado em } \\
\text { uma Auditoria Oficial de Acreditação. }\end{array}$ \\
\hline Etapa 14 & $\begin{array}{l}\text { Agendar a Auditoria Oficial de Acreditação e } \\
\text { tomar as providências necessárias }\end{array}$ & $\begin{array}{l}\text { A Alta Administração do hospital deve } \\
\text { contatar uma Agência Acreditadora, realizando } \\
\text { o agendamento da Auditoria Oficial de } \\
\text { Acreditação. }\end{array}$ \\
\hline
\end{tabular}

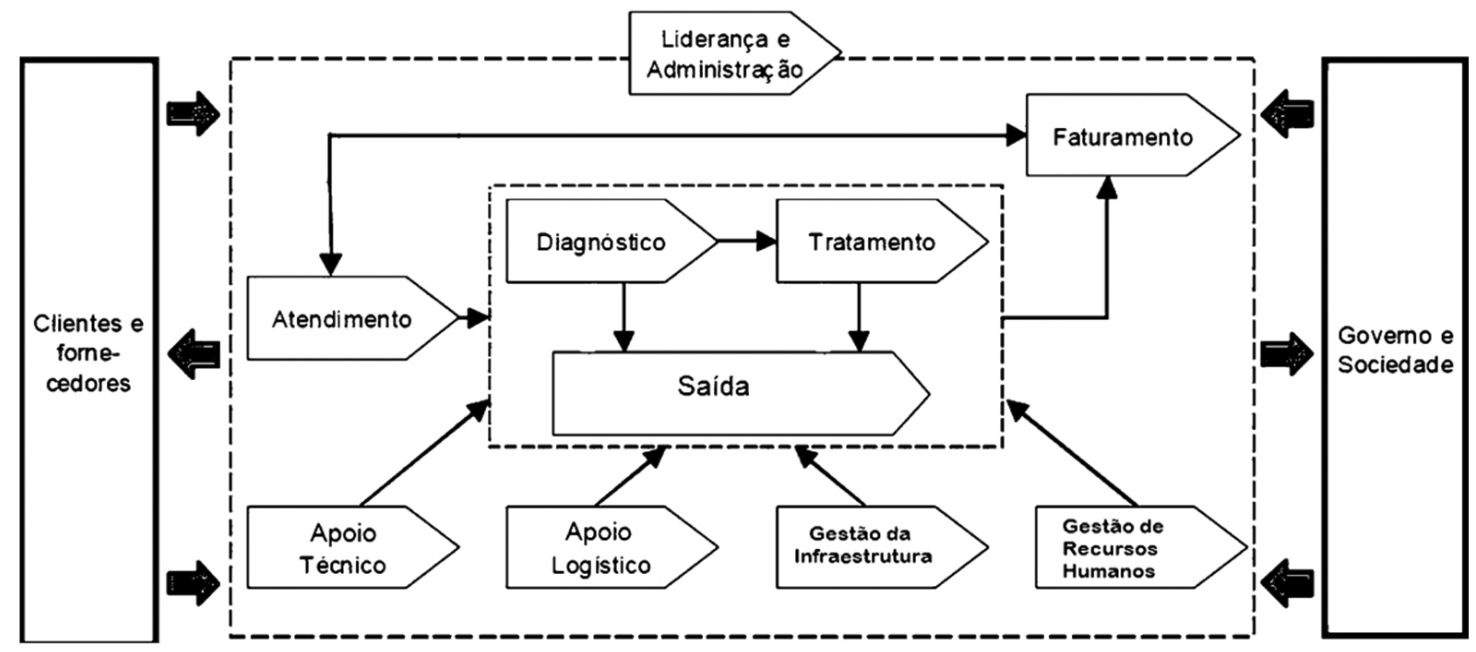

Figura 2. Macroprocessos do Hospital A e o Macrofluxo associado.

em observar e monitorar os processos fisiológicos dos pacientes internados. Os fornecedores são Laboratório e Radioimagem (raios X, ultrassom e tomografia). Os microprocessos de Diagnóstico são: Diagnóstico por Imagem e Diagnóstico Laboratorial.

Os microprocessos de Saída referem-se ao preparo da alta, à alta propriamente dita, ao seguimento ambulatorial e ao controle. São microprocessos ligados ao Acolhimento Domiciliar, à Enfermagem e, em caso de óbito, ligados ao Morgue onde é realizada a necropsia (patologia clínica, citologia, histologia). Os microprocessos de Saída são: Alta, Transferência e Óbito. Por fim, desdobraram-se os macroprocessos em microprocessos e suas respectivas atividades.

\subsubsection{Documentação de procedimentos}

Depois de mapear os processos realizaram-se a formalização e a documentação dos procedimentos dos setores diretamente envolvidos nos macroprocessos críticos. Foram documentados os procedimentos de enfermagem, farmácia, fisioterapia e radiologia.

Constatou-se que a documentação desses procedimentos estava em fase de elaboração pelas chefias dos setores. Porém, o modelo que seria adotado era inadequado, extenso, com quantidade excessiva de informações e campos de preenchimento desnecessários ("Resultados Esperados", "Materiais Necessários", "Referências Bibliográficas"). 
Foi proposto e implantado outro modelo de procedimento operacional mais adequado, prático e de fácil visualização, usando ferramentas como $5 \mathrm{~W} 1 \mathrm{H}$ e fluxograma. O objetivo desse novo layout era facilitar a capacitação dos profissionais e sua compreensão.

Realizaram-se sessões de treinamento com os chefes dos setores de enfermagem, farmácia, radiologia e fisioterapia, visando explicar conceitos envolvidos no novo layout como: a simbologia usada no fluxograma, o significado do $5 \mathrm{~W} 1 \mathrm{H}$ e o modo de preenchimento dos campos do 5W1H. Esses conceitos deveriam ser compreendidos pelos profissionais para que conseguissem repassar e adequar as informações do layout antigo ao novo.

\subsubsection{Plano de Ação II: mapeamento, análise e tratamento de riscos e eventos adversos}

O Plano de Ação II identificou os riscos profissionais (relativos ao tratamento prestado aos pacientes) inerentes aos microprocessos críticos: Consulta Médica, Assistência de Enfermagem, Assistência de Farmácia, Diagnóstico por Imagem, Alta, Transferência e Saída.

Os riscos foram ponderados segundo sua gravidade (prejuízos pela ocorrência do risco) e com sua frequência (assiduidade de ocorrência do risco), por meio de escala crescente variando de 1 (pouco grave/ pouco frequente) a 5 (muito grave/muito frequente). Com isso, foram determinados os riscos críticos e implantadas medidas preventivas à ocorrência destes.

O Plano de Ação II envolveu a realização de tarefas como: identificação dos riscos profissionais de cada atividade dos macroprocessos críticos; identificação dos riscos críticos dos macroprocessos críticos; implantação de registros de notificação da ocorrência desses riscos; implantação de registros de Tecnovigilância (riscos relacionados aos equipamentos e materiais de uso médico e de enfermagem) e Farmacovigilância (riscos relacionados a reações adversas a medicamentos e a inefetividade de medicamentos); implantação de medidas preventivas e corretivas à ocorrência dos riscos críticos mapeados.

Os riscos críticos foram os de maior pontuação. Para cada risco crítico, implantaram-se:

- Dispositivos de gestão à vista: pulseiras coloridas e carimbos de alerta para identificar pacientes com alto risco de queda, flebite e úlcera por pressão;

- Registros de avaliação individual de riscos para cada paciente internado;

- Protocolos de Prevenção à Ocorrência do Risco;

- Fichas de Notificação de Eventos Adversos para registrar a ocorrência do risco crítico mapeado, possibilitando o monitoramento mensal de sua ocorrência.

\subsubsection{Plano de ação III: concepção e implantação de indicadores de desempenho}

Aos macroprocessos críticos, foram propostos e implantados indicadores a fim de medir e monitorar seus desempenhos e os riscos. Entre os indicadores propostos estão:

- Macroprocesso Tratamento: taxa de prescrições médicas suspensas, taxa de erros de prescrição médica (Consulta Médica); incidência de flebite, incidência de úlcera por pressão, incidência de queda de paciente, incidência de erros de medicação (Assistência de Enfermagem); taxa de medicamentos entregues fora do prazo, índice de falta de medicamentos, taxa de reações adversas a medicamentos (Assistência de Farmácia); etc.;

- Para o macroprocesso Diagnóstico: taxa de perda de filme de raios $\mathrm{X}$, taxa de filmes com artefatos, taxa de exame de imagem por paciente, taxa de repetição de exame; etc.;

- Para o macroprocesso Saída: taxa de alta inferior a 48 horas, taxa de rotatividade de leitos (Alta); tempo de espera para transferência, incidência de pedido de transferência de paciente (Transferência); ocorrência de óbito após 72 horas de internação (Óbito); etc.

\subsection{Avaliação e monitoramento dos resultados da pesquisa-ação}

Os resultados dos Planos de Ação foram avaliados por uma pesquisa de opinião para aferir a percepção dos profissionais do hospital sobre as ações implantadas. Aplicou-se a questão: "Como você avalia as ações implantadas (registros, novo layout dos procedimentos, carimbos, folders, pulseiras, registros de não conformidades, palestras)?"

Para $72 \%$, as ações produziram melhorias na rotina de trabalho. Para 10\%, as ações não melhoraram nem pioraram a rotina de trabalho e $18 \%$ dos participantes avaliaram negativamente as ações, alegando que estas dificultaram a realização das tarefas rotineiras. Foram implantadas plenamente 23 das 48 ações (48\%) inicialmente previstas pela pesquisa-ação.

Foram planejadas 52\% das medidas e deverão ser implantadas no decorrer de 2012. Entre tais ações estão: sinalização por placas dos setores mais procurados pelos pacientes; compatibilização do número de profissionais de enfermagem e de farmácia com a demanda atendida; formação de uma Comissão de Farmacovigilância; capacitação dos profissionais 
para notificação voluntária; publicação de boletins informativos.

Depois da pesquisa-ação, os pontos de aprimoramento identificados para o roteiro foram:

- Realizar o mapeamento dos macrofluxos do hospital, por meio da identificação do Perfil Epidemiológico, isto é, pela identificação dos tipos de doenças mais atendidas pelo hospital. Assim, será possível identificar os fluxos que são mais críticos ao hospital, fundamentando-se em dados reais;

- Identificar o Perfil Epidemiológico via Código Internacional de Doenças (CID), inserindo um campo para preenchimento deste código nas fichas de atendimento;

- Antes da etapa de mapeamento de riscos, um profissional de cada setor do hospital deve ser nomeado e capacitado para compor uma Comissão de Gerenciamento de Riscos e Eventos Adversos. Isso facilitaria a realização do mapeamento de riscos tornando-o mais eficiente e compatível com os processos do hospital.

\section{Proposição de roteiro para implantação da Acreditação Hospitalar}

Realizados os ajustes necessários no roteiro preliminar, propôs-se o Roteiro para Implantação da Acreditação Hospitalar. Este é mostrado na Figura 3 e descrito no Quadro 3, e tem o objetivo de orientar hospitais interessados em adequar sua gestão à Acreditação.

O Roteiro foi dividido em cinco Macrofases. As etapas de 1 a 5 compõem a Macrofase I e estendem-se desde a decisão da Alta Administração em adotar a Acreditação até a formação e capacitação de um Comitê para condução da adequação a seus requisitos e início da adequação à Acreditação. A Macrofase II, das etapas 6 a 10, busca mapear e documentar processos e procedimentos do hospital, a partir dos tipos de doença mais atendidos.

As etapas de 11 a 13 formam a Macrofase III de estruturação da Gestão de Riscos. As etapas 14 e 15 compõem a Macrofase IV de estruturação da Gestão por Evidências.

A Macrofase V, composta pelas etapas 16 e 17, refere-se à finalização do processo de adequação da gestão. Assim, os profissionais realizam uma auditoria interna em cada setor do hospital, repassando e conferindo o cumprimento de todos os requisitos avaliados na Auditoria Oficial de Acreditação. Na etapa 17, a Alta Administração do Hospital contata uma Agência Acreditadora para agendar a Auditoria de Acreditação.

\section{Considerações finais}

Os resultados observados por este trabalho vão ao encontro das conclusões de Noronha, Travassos e Rosa (1999), Feldman e Cunha (2006) e La Forgia e Couttolenc (2009) de que o processo brasileiro de Acreditação é incipiente (apenas 2,4\% dos hospitais do País são Acreditados).

A conclusão desses autores também foi observada no escopo da pesquisa-ação relatada neste artigo, quando se constatou um baixo grau de compreensão dos conceitos e requisitos de Acreditação pelos profissionais do Hospital em que foi conduzida a pesquisa ação, dificultando, consequentemente, a condução da implantação. Essa observação está de acordo com as conclusões de Novaes e Schiesari (2003), Smits et al. (2007), La Forgia e Couttolenc (2009) e Jaafaripooyan, Agrizzi e Akbari-Haghighi (2011), sobre a falta de um roteiro estruturado de orientação para a implantação dos requisitos de Acreditação, principalmente em hospitais de menor porte.

O roteiro proposto, apesar de aplicado em apenas um hospital, busca auxiliar os hospitais brasileiros na condução do processo de implantação dos requisitos de Acreditação. A experiência com o roteiro foi bem-sucedida, pois iniciou e planejou a adequação da gestão do Hospital A aos requisitos de Acreditação, deixando-os implantados ou em implantação.

Foram implantadas iniciativas básicas de Gestão da Qualidade, como a documentação de procedimentos operacionais, implantação de registros de não conformidades e de dispositivos de gestão à vista (pulseiras, carimbos e placas de identificação de leitos). A pesquisa-ação gerou aprendizagem, aos profissionais do Hospital A, sobre Acreditação, seus requisitos e diretrizes, solucionando problemas de falta de compreensão destes profissionais acerca do processo de Acreditação.

Apesar do sucesso na aplicação do roteiro, maior número de aplicações deve ocorrer a fim de assegurar a eficácia de implantação da Acreditação via roteiro. Sugere-se a criação de uma escala de maturidade para avaliar o grau em que práticas e procedimentos de trabalho estão implementados e incorporados à rotina de atividades dos hospitais.

As etapas do roteiro podem ser modificadas para adaptar-se a cada realidade, cabendo ao hospital decidir se a realização de determinada etapa é viável. Porém, há iniciativas que podem garantir maior eficácia ao roteiro. É importante que o processo de implantação da Acreditação seja conduzido e desdobrado a partir da alta administração, a qual deve introduzir e disseminar, aos demais níveis hierárquicos, esse processo, sua importância, diretrizes e conceitos, conforme sugerem 
Etapa 1: Conscientizar e Mobilizar os profissionais do hospital quanto à implantação dos requisitos de Acreditação

Etapa 2: Formar e Capacitar Comitê de condução da Adequação da gestão aos requisitos de Acreditação

Etapa 3: Capacitar e Educar os profissionais do hospital em conceitos, requisitos e diretrizes da Acreditação

Etapa 4: Buscar a Motivação e o Envolvimento dos profissionais para o processo de implantação

Etapa 5: Iniciar a Adequação da Gestão aos requisitos de Acreditação

Etapa 6: Identificar o número de atendimentos mensais prestados por tipo de doença, conforme código CDD

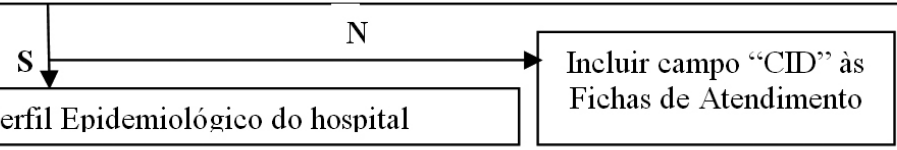

Etapa 7: Determinar Perfil Epidemiológico do hospital

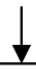

Etapa 8: Determinar macrofluxos e microfluxos do hospital

Etapa 9: Identificar os processos críticos do hospital

Etapa 10: Documentar procedimentos operacionais (protocolos) para os processos críticos

Etapa 11: Identificar os riscos inerentes aos processos críticos

Etapa 12: Documentar os riscos críticos: registros de notificação, protocolos preventivos e dispositivos de gestão à vista

Comunicar os profissionais sobre o andamento das ações de Adequação da Gestão do hospital aos requisitos de Acreditação

Etapa 13: Compor Comissão de Gerenciamento (Riscos e Qualidade)

Etapa 14: Implantar indicadores de desempenho aos: processos críticos, riscos críticos, clientes, financeiros, e de aprendizado

Etapa 15: Monitorar e Melhorar o desempenho dos processos críticos e de seus indicadores por meio de: capacitação, análise crítica, e investimentos em sensibilização, recursos humanos e infra-estrutura

Etapa 16: Realizar Auditoria Interna em cada setor do Hospital como preparação à Auditoria Oficial de Acreditação e providenciar os eventuais ajustes necessários

Etapa 17: Agendar a Auditoria Oficial de Acreditação Plena e tomar as providências necessárias

Figura 3. Roteiro para Implantação dos requisitos de Acreditação. 
Quadro 3. Etapas do Roteiro para Implantação da Acreditação em hospitais.

\begin{tabular}{|c|c|c|c|}
\hline $\begin{array}{c}\text { Fases do } \\
\text { Roteiro de } \\
\text { implantação }\end{array}$ & $\begin{array}{c}\text { Etapas do } \\
\text { Roteiro } \\
\text { de implantação }\end{array}$ & Tarefas da Etapa & Descrição da Tarefa \\
\hline \multirow{5}{*}{ Macrofase I } & Etapa 1 & $\begin{array}{l}\text { Conscientizar e Mobilizar } \\
\text { os profissionais do hospital } \\
\text { quanto à implantação dos } \\
\text { requisitos de Acreditação }\end{array}$ & $\begin{array}{l}\text { A Alta Administração deve iniciar o processo } \\
\text { de conscientização e mobilização dos } \\
\text { profissionais do hospital para o processo de } \\
\text { implantação da Acreditação a ser realizado. } \\
\text { Para tal, pode-se realizar palestras, reuniões, } \\
\text { visitas aos setores; trazer profissionais de } \\
\text { hospitais Acreditados para que estes realizem } \\
\text { palestras aos profissionais; etc. A etapa } 1 \text { busca } \\
\text { evidenciar a participação da Alta Administração } \\
\text { no processo de implantação. }\end{array}$ \\
\hline & Etapa 2 & $\begin{array}{l}\text { Formar e Capacitar } \\
\text { Comitê de condução da } \\
\text { Adequação da gestão aos } \\
\text { requisitos de Acreditação }\end{array}$ & $\begin{array}{l}\text { Um comitê para conduzir a implantação dos } \\
\text { requisitos de Acreditação deve ser formado, } \\
\text { contendo membros da Alta Administração e } \\
\text { chefes de setores. }\end{array}$ \\
\hline & Etapa 3 & $\begin{array}{l}\text { Capacitar e Educar os } \\
\text { profissionais do hospital } \\
\text { quanto aos conceitos, valores, } \\
\text { requisitos e diretrizes da } \\
\text { Acreditação }\end{array}$ & $\begin{array}{l}\text { O Comitê deve promover a capacitação e } \\
\text { a educação dos profissionais do hospital } \\
\text { nos conceitos, requisitos e diretrizes da } \\
\text { Acreditação, por meio de palestras, vídeos } \\
\text { explicativos, palestras com profissionais de } \\
\text { hospitais Acreditados. }\end{array}$ \\
\hline & Etapa 4 & $\begin{array}{l}\text { Buscar a Motivação e } \\
\text { o Envolvimento dos } \\
\text { profissionais do hospital } \\
\text { para com o processo de } \\
\text { implantação da Acreditação }\end{array}$ & $\begin{array}{l}\text { Deve-se envolver e motivar os profissionais } \\
\text { do hospital no processo de implantação da } \\
\text { Acreditação por meio de cartazes, mensagens } \\
\text { de incentivos em cada setor, premiações, } \\
\text { reuniões de brainstorming e participação nas } \\
\text { reuniões sobre as ações futuras e em andamento } \\
\text { do processo. }\end{array}$ \\
\hline & Etapa 5 & $\begin{array}{l}\text { Iniciar a Adequação da } \\
\text { Gestão aos requisitos de } \\
\text { Acreditação da ONA }\end{array}$ & $\begin{array}{l}\text { Refere-se ao início das ações de Adequação da } \\
\text { gestão aos requisitos de Acreditação. }\end{array}$ \\
\hline \multirow{3}{*}{ Macrofase II } & Etapa 6 & $\begin{array}{l}\text { Identificar o número de } \\
\text { atendimentos mensais } \\
\text { prestados por tipo de doença, } \\
\text { conforme CID-10 }\end{array}$ & $\begin{array}{l}\text { O Hospital deve, inicialmente, medir o número } \\
\text { de atendimentos classificando-os segundo o } \\
\text { tipo de doença expresso pelo código CID-10. }\end{array}$ \\
\hline & Etapa 7 & $\begin{array}{l}\text { Determinar Perfil } \\
\text { Epidemiológico do Hospital }\end{array}$ & $\begin{array}{l}\text { Distribuir os tipos de doença medidos na Etapa } \\
6 \text { em percentuais e focalizar os tipos mais } \\
\text { frequentes. }\end{array}$ \\
\hline & Etapa 8 & $\begin{array}{l}\text { Determinar macrofluxos e } \\
\text { microfluxos dos atendimentos } \\
\text { mais frequentes }\end{array}$ & $\begin{array}{l}\text { Identificar, em registros e mapas, o fluxo } \\
\text { seguido pelos atendimentos mais frequentes e } \\
\text { o relacionamento entre todos os processos do } \\
\text { Hospital. }\end{array}$ \\
\hline \multirow[b]{2}{*}{ Macrofase II } & Etapa 9 & $\begin{array}{l}\text { Identificar os processos } \\
\text { críticos do Hospital }\end{array}$ & $\begin{array}{l}\text { Identificar, entre os processos mapeados, } \\
\text { aqueles que são críticos. }\end{array}$ \\
\hline & Etapa 10 & $\begin{array}{l}\text { Documentar procedimentos } \\
\text { operacionais (protocolos) } \\
\text { para os processos críticos }\end{array}$ & $\begin{array}{l}\text { Elaborar procedimentos operacionais } \\
\text { (protocolos) associados aos processos críticos. }\end{array}$ \\
\hline
\end{tabular}


Quadro 3. Continuação...

\begin{tabular}{|c|c|c|c|}
\hline $\begin{array}{c}\text { Fases do } \\
\text { Roteiro de } \\
\text { implantação }\end{array}$ & $\begin{array}{c}\text { Etapas do } \\
\text { Roteiro } \\
\text { de implantação }\end{array}$ & Tarefas da Etapa & Descrição da Tarefa \\
\hline \multirow{3}{*}{ Macrofase III } & Etapa 11 & $\begin{array}{l}\text { Identificar os riscos inerentes } \\
\text { aos processos críticos }\end{array}$ & $\begin{array}{l}\text { Identificar os riscos (ambientais, assistenciais, } \\
\text { profissionais, clínicos, etc.), documentando-os. }\end{array}$ \\
\hline & Etapa 12 & $\begin{array}{l}\text { Documentar os riscos } \\
\text { críticos: registros de } \\
\text { notificação, protocolos } \\
\text { preventivos e dispositivos de } \\
\text { gestão à vista }\end{array}$ & $\begin{array}{l}\text { Identificar os riscos mais críticos aos } \\
\text { processos mapeados, documentando-os para } \\
\text { monitoramento e melhoria. }\end{array}$ \\
\hline & Etapa 13 & $\begin{array}{l}\text { Compor Comissão de } \\
\text { Gerenciamento (Riscos e } \\
\text { Qualidade) }\end{array}$ & $\begin{array}{l}\text { Estruturar uma comissão para monitoramento } \\
\text { e operacionalização das práticas de Gestão da } \\
\text { Qualidade e de Risco. }\end{array}$ \\
\hline Macrofase IV & Etapa 14 & $\begin{array}{l}\text { Implantar indicadores aos } \\
\text { processos críticos, riscos, } \\
\text { clientes, financeiros e de } \\
\text { aprendizado }\end{array}$ & $\begin{array}{l}\text { As atividades da Gestão recém-implantada } \\
\text { devem ser monitoradas por meio de indicadores } \\
\text { e seu desempenho deve ser analisado e } \\
\text { melhorado (Gestão por Evidências). }\end{array}$ \\
\hline \multirow[t]{2}{*}{ Macrofase IV } & Etapa 15 & $\begin{array}{l}\text { Monitorar e Melhorar o } \\
\text { desempenho dos processos } \\
\text { críticos e de seus indicadores } \\
\text { por meio de capacitação, } \\
\text { análise crítica e investimentos } \\
\text { em sensibilização, recursos } \\
\text { humanos e infraestrutura }\end{array}$ & $\begin{array}{l}\text { Realizar, periodicamente, o monitoramento } \\
\text { dos indicadores para avaliação do desempenho } \\
\text { das práticas de gestão implementadas nas } \\
\text { etapas anteriores desta sistemática. Melhorar } \\
\text { continuamente as atividades. }\end{array}$ \\
\hline & & $\begin{array}{l}\text { Comunicar aos profissionais } \\
\text { o andamento das ações de } \\
\text { Adequação da Gestão do } \\
\text { hospital aos requisitos de } \\
\text { Acreditação }\end{array}$ & $\begin{array}{l}\text { No decorrer do processo de Adequação, } \\
\text { as ações de implantação devem ser, } \\
\text { continuamente, comunicadas pelo Comitê } \\
\text { aos profissionais. Isso pode ocorrer por meio } \\
\text { de reuniões, boletins informativos, notícias } \\
\text { em jornais internos, palestras, etc. A Alta } \\
\text { Administração deve participar de tais reuniões } \\
\text { e palestras, evidenciando seu envolvimento no } \\
\text { processo. }\end{array}$ \\
\hline \multirow{2}{*}{ Macrofase V } & Etapa 16 & $\begin{array}{l}\text { Realizar Auditoria Interna } \\
\text { em cada setor do Hospital } \\
\text { como preparação à Auditoria } \\
\text { Oficial e providenciar os } \\
\text { eventuais ajustes necessários }\end{array}$ & $\begin{array}{l}\text { Realizar, em cada setor do Hospital, uma } \\
\text { Auditoria Interna, checando e repassando o } \\
\text { cumprimento de cada requisito avaliado em } \\
\text { uma Auditoria Oficial de Acreditação. }\end{array}$ \\
\hline & Etapa 17 & $\begin{array}{l}\text { Agendar a Auditoria Oficial } \\
\text { de Acreditação e tomar as } \\
\text { providências necessárias }\end{array}$ & $\begin{array}{l}\text { A Alta Administração do Hospital deve } \\
\text { contatar uma Agência Acreditadora, realizando } \\
\text { o agendamento da Auditoria Oficial de } \\
\text { Acreditação, acompanhando os resultados e } \\
\text { providenciando os ajustes. }\end{array}$ \\
\hline
\end{tabular}

Zamany, Hodell e Savage (2002), Hansson e Klefsjo (2003), François e Pomey (2005), François, Boyer e Weil (2008) e Wardhani et al. (2009).

Conforme recomendam Kisil (2004) e La Forgia e Couttolenc (2009), é importante que uma equipe permanente de implantação seja formada na unidade hospitalar em processo de Acreditação. Tal equipe deve ser multidisciplinar com representantes de cada setor da estrutura do hospital. Cada membro deve ser capacitado em auditoria interna para Acreditação, pois a equipe conduzirá o processo de implantação, atuará na conscientização dos profissionais do hospital e estimulará o envolvimento destes no processo de Acreditação.

Como motivação à implantação, deve-se, continuamente, comunicar, a todos os profissionais do hospital, o andamento das ações em curso, fazendo-os participar de reuniões, incentivando a proposição 
de sugestões e adesão aos novos procedimentos de trabalho. Assim, mesmo que ocorram adaptações às etapas do roteiro, por meio dessas iniciativas, tem-se a base para implantação bem-sucedida da Acreditação, destacando o papel e o comprometimento dos profissionais e da Alta Administração no processo de implantação.

As perspectivas para a Acreditação Hospitalar brasileira são a alteração dos rumos das práticas associadas à gestão hospitalar e à gestão da qualidade em hospitais, consolidando-se como um padrão de referência em termos de práticas, avaliação e gestão de tais serviços, como ocorre em nações em que esse processo de Acreditação encontra-se em estado de maior maturidade e difusão, por exemplo, na França, Alemanha, Espanha, Inglaterra e EUA.

\section{Referências}

ANTUNES, F. L.; RIBEIRO, J. D. Acreditação Hospitalar: Um Estudo de Caso. Produção Online, v. 5, n. 1, p. 1-27, 2005.

BONATO, V. L. Gestão em Saúde: Programas de Qualidade em Hospitais. São Paulo: Ícone, 2007. 119 p.

BURMESTER, H.; PEREIRA, J. C.; SCARPI, M. J. Modelo de Gestão para organizações de Saúde. Revista de Administração em Saúde, v. 9, n. 37, p. 125-132, out./dez. 2007.

CORREIA, L. C.; MELO, M. N.; MEDEIROS, D. D. Modelo de diagnóstico e implementação de um sistema de gestão da qualidade: estudo de caso. Produção, v. 16, n. 1, p. 111-125, jan./abr. 2006. http://dx.doi. org/10.1590/S0103-65132006000100010

COUGHLAN, P.; COGHLAN, D. Action research for operations management. International Journal of Operations \& Production Management, v. 22 , n. 2 , p. 220-240, 2002. http://dx.doi. org/10.1108/01443570210417515

COUTO, R. C.; PEDROSA, T. G. Avaliação das Metodologias Certificáveis de Garantia da Qualidade. In: COUTO, R. C.; PEDROSA, T. G. (Coord.). Hospital: Acreditação e Gestão em Saúde. 2. ed. Rio de Janeiro: Guanabara Koogan, 2007. p. 301-313.

D'INNOCENZO, M. D.; ADAMI, N. P.; CUNHA, I. O. O movimento pela qualidade nos serviços de saúde e enfermagem. Revista Brasileira de Enfermagem, v. 59, n. 1, p. 84-88, jan./fev. 2006. http://dx.doi.org/10.1590/ S0034-71672006000100016

FELDMAN, L. B.; CUNHA, I. C. Identification of result evaluation criteria for nursing service in hospital accreditation programs. Revista Latino-Americana de Enfermagem, v. 14, n. 4, p. 540-545, 2006. http:// dx.doi.org/10.1590/S0104-11692006000400011

FELDMAN, L. B.; GATTO, M. F.; CUNHA, I. K. História da evolução da qualidade hospitalar: dos padrões à acreditação. Acta Paulista de Enfermagem, v. 18, n. 2, p. 213-219, 2005. http://dx.doi.org/10.1590/ S0103-21002005000200015

FRANÇOIS, P.; BOYER, L.; WEIL, G. Implantation of quality management in medical department of teaching hospital: Accelerators and inhibitors. Revue d'Epidemiologique et de Santé Publique, n. 56, p. 189-195, 2008.

FRANÇOIS, P.; POMEY, M. P. Implantation de La Gestion de La Qualité dans lês hopitaux français, jeux d'acteur et transformations induites. Revue Epidemiologique Santé Publique, n. 53, p. 4-11, 2005.

FORTES, M. T.; MATTOS, M. A.; BAPTISTA, T. W. Acreditação ou Acreditações? Um comparativo entre a acreditação na França, no Reino Unido e na Catalunha. Revista da Associação Médica Brasileira, v. 57, n. 2, p. 239-246, mar./abr. 2011. http://dx.doi.org/10.1590/ S0104-42302011000200025

GURGEL JUNIOR, G. D.; VIEIRA, M. F. Qualidade total e administração hospitalar: explorando disjunções conceituais. Ciência e Saúde Coletiva, v. 7, n. 2, p. 325-334, 2002. http://dx.doi.org/10.1590/ S1413-81232002000200012

HANSSON, J.; KLEFSJO, B. A Core value model for implementing total quality management in small organization. TQM Magazine, v. 15, n. 2, p. 71-81, 2003. http://dx.doi.org/10.1108/09544780310461071

JAAFARIPOOYAN, E.; AGRIZZI, D.; AKBARIHAGHIGHI, F. A. Healthcare accreditation systems: further perspectives on performance measures. International Journal for Quality in Health Care, p. 1-12, set. 2011. http://dx.doi.org/10.1093/intqhe/ mzr063

JOINT COMMISSION. About the Joint Commission. 2011. Disponível em: <http://www.jointcommission. org/about_us/about_the_joint_commission_main.aspx>. Acesso em: 14 jan. 2011.

KISIL, M. Hospital Quality. Sao Paulo: Banco Mundial, 2004.

KLUCK, M. et al. A Gestão da Qualidade Hospitalar do Hospital das Clínicas de Porto Alegre: implementação e validação de indicadores. Revista de Administração em Saúde, v. 10, n. 40, p. 97-102, jul./set. 2008.

KUBALLA, J. Aspects and Implementation of Effective Quality Management Systems. Munich: Grin Verlagv, 2007. $40 \mathrm{p}$.

LA FORGIA, G. M.; COUTTOLENC, B. F. Desempenho hospitalar no Brasil: em busca da excelência. São Paulo: Editora Singular, 2009. 496 p.

LAGIOIA, U. T. et al. A gestão por processo gera melhoria da qualidade e redução de custos: $\mathrm{O}$ caso da unidade de ortopedia e traumatologia do hospital das clínicas da Universidade Federal de Pernambuco. Revista Contabilidade \& Finanças, v. 19, n. 48, p. 77-90, set./dez. 2008. http://dx.doi.org/10.1590/ S1519-70772008000300007

MACINATI, M. S. The relationship between quality management systems and organizational performance in the Italian National Health Service. Health Policy, n. 85 , p. 228-241, 2008. http://dx.doi.org/10.1016/j. healthpol.2007.07.013

MATHEIS, A. Em busca de saídas para a revitalização do setor. Revista de Administração Hospitalar, v. 2, n. 2, p. 41-43, set./dez. 2006.

NOGUEIRA, L. C. Gerenciando pela Qualidade Total na Saúde. 3. ed. Belo Horizonte: Livrocerto, 2008. 134 p. 
NORONHA, T. C.; TRAVASSOS, C. M.; ROSA, M. L. Quality improvement initiatives in Brazil: a progress report. Joint Commission Journal on Quality Improvement, v. 25, n. 11, p. 565-573, 1999.

NOVAES, H. M.; SCHIESARI, L. M. Accreditation of health service network: challenges and perspectives. World Hospitals and Health Services: The Official Journal of the International Hospital Federation, v. 39, n. 2, p. 18-23, 2003.

OLIVEIRA, S. A vivência da implantação do programa de qualidade total: Um estudo de caso. Produção, v. 8, n. 1, p. 17-28, jul. 1998. http://dx.doi.org/10.1590/ S0103-65131998000100002

ORGANIZAÇÃO NACIONAL DE ACREDITAÇÃO - ONA. Manual das organizações prestadoras de serviços de saúde. 6. ed. Brasília: ONA, 2010. 203 p.

ORGANIZAÇÃO NACIONAL DE ACREDITAÇÃO - ONA. 67\% dos Estados possuem serviços Acreditados pelo SBA/ONA. Brasília: ONA, 2011. Disponível em: $<$ https://www.ona.org.br/Noticia/83/67-dos-Estadospossuem-Servicos-Acreditados-pelo-SBA-ONA>. Acesso em: 02 jan. 2011.

OVRETVEIT, J.; GUSTAFSON, D. Evaluation of Quality Improvement Programmes. Quality Safety Care, n. 11, p. 270-275, 2002. http://dx.doi.org/10.1136/qhc.11.3.270

PERTENCE, P. P.; MELLEIRO, M. M. Implantação de ferramenta de gestão de qualidade em hospital universitário. Revista da Escola de Enfermagem da USP, v. 44, n. 4, p. 1024-1031, dez. 2010. http://dx.doi. org/10.1590/S0080-62342010000400024

PFEIFER, T. Quality Management: Strategies, Methods, Techniques. Cincinnati: HanserGardner Publications, 2002. 587 p.
SATIA, J.; DOHLIE, M. B. Achieving Total Quality Management in Public Health System. Journal of Health Management, v. 1, n. 2, p. 301-322, Oct 1999. http:// dx.doi.org/10.1177/097206349900100208

SCHYVE, P. Models for relating performance measurement and accreditation. International Journal of Health Planning and Management, v. 10, n. 3, p. 231-241, jul/ oct. 1995. http://dx.doi.org/10.1002/hpm.4740100309

SMITS, P. A. et al. Conceptualizing performance in accreditation. International Journal for Quality in Health Care, v. 20, n. 1, p. 47-52, nov. 2007.

TACHIZAWA, T.; SCAICO, O. Qualidade na Gestão por Processos. 2. ed. São Paulo: Atlas, 2006. 382 p.

TORELLI, L. C.; FERREIRA, J. A. Qualidade total proposta de um modelo para implantação. Gestão \& Produção, v. 2, n. 3, p. 281-296, dec. 1995. http://dx.doi. org/10.1590/S0104-530X1995000300004

VECINA NETO, G.; MALIK, A. M. Tendências na Assistência Hospitalar. Ciência e Saúde Coletiva, v. 12 , n. 4, p. 825-839, jul/ago. 2007. http://dx.doi. org/10.1590/S1413-81232007000400002

VITNER, G. et al. ISO 9001 in a neonatal intensive care unit. International Journal of Health Care Quality Assurance, v. 24, n. 8, p. 644-653, 2011. http://dx.doi. org/10.1108/09526861111174206

WARDHANI, V. et al. Determinants of Quality Management Systems implementation in hospitals. Health Policy, n. 89, p. 239-251, 2009. http://dx.doi.org/10.1016/j. healthpol.2008.06.008

ZAMANY, Y.; HODDELL, S. J.; SAVAGE, B. M. Understanding the difficulties of implementing quality management in Yemen. TQM Magazine, v. 14, n. 4, p. 240-247, 2002. http://dx.doi. org/10.1108/09544780210429852 
